\title{
Efforts to sustain biodiversity fall short
}

But the issue is gaining attention as nations prepare for next year's summit.

With nations admitting that they will fail to achieve their goal of significantly cutting biodiversity loss by 2010, a flurry of work is under way to develop new, more robust targets and ways of monitoring progress. These must be ready by next October, when the 193 parties to the Convention on Biological Diversity (CBD) meet in Nagoya, Japan.

The summit will be the culmination of a series of events focused on the loss of biodiversity. The General Assembly of the United Nations has declared 2010 the International Year of Biodiversity, and governments will meet in London in January to start thrashing out a new set of biodiversity protections. In September, world leaders will convene in New York for a UN meeting on the topic.

In 2002, ten years after the CBD was signed, nations adopted a 2010 target in which they pledged to achieve "a significant reduction of the current rate of biodiversity loss at the global, regional and national level". But conservation leaders acknowledge that nations will come to Nagoya having fallen short. "We will not meet the target," says Matt Walpole, head of ecosystem assessment at the United Nations Environment Programme's World Conservation Monitoring Centre in Cambridge, UK. "Biodiversity is still in decline. This is because a lot of the key threats, such as change in land cover, habitat loss and pollution, are still not under control. And then new emerging threats, such as climate change, are coming through."

The parties to the convention are expected to set targets that are more specific than the current one. Nations could set a long-term goal for biodiversity in 2050, as well as an array of 2020 targets.

For example, Walpole suggests that targets could include ensuring that no new invasions by non-indigenous species take place. Another potential option would be setting a benchmark that $80-90 \%$ of all fisheries have to be be sustainable, he adds. The new targets will

\begin{tabular}{|l|l|l|}
\hline \multicolumn{3}{|l|}{ SPECIES AT RISK } \\
\hline $\begin{array}{l}\text { Groups evaluated } \\
\text { most completely }\end{array}$ & $\begin{array}{l}\text { Number of } \\
\text { described species }\end{array}$ & $\begin{array}{l}\text { Percentage } \\
\text { threatened }\end{array}$ \\
\hline Gymnosperms & 1,021 & $32 \%$ \\
\hline Amphibians & 6,433 & $29 \%$ \\
\hline Mammals & 5,490 & $21 \%$ \\
\hline Birds & 9,998 & $12 \%$ \\
\hline \multicolumn{3}{|l|}{ Source: International Union for Conservation of Nature } \\
\hline
\end{tabular}

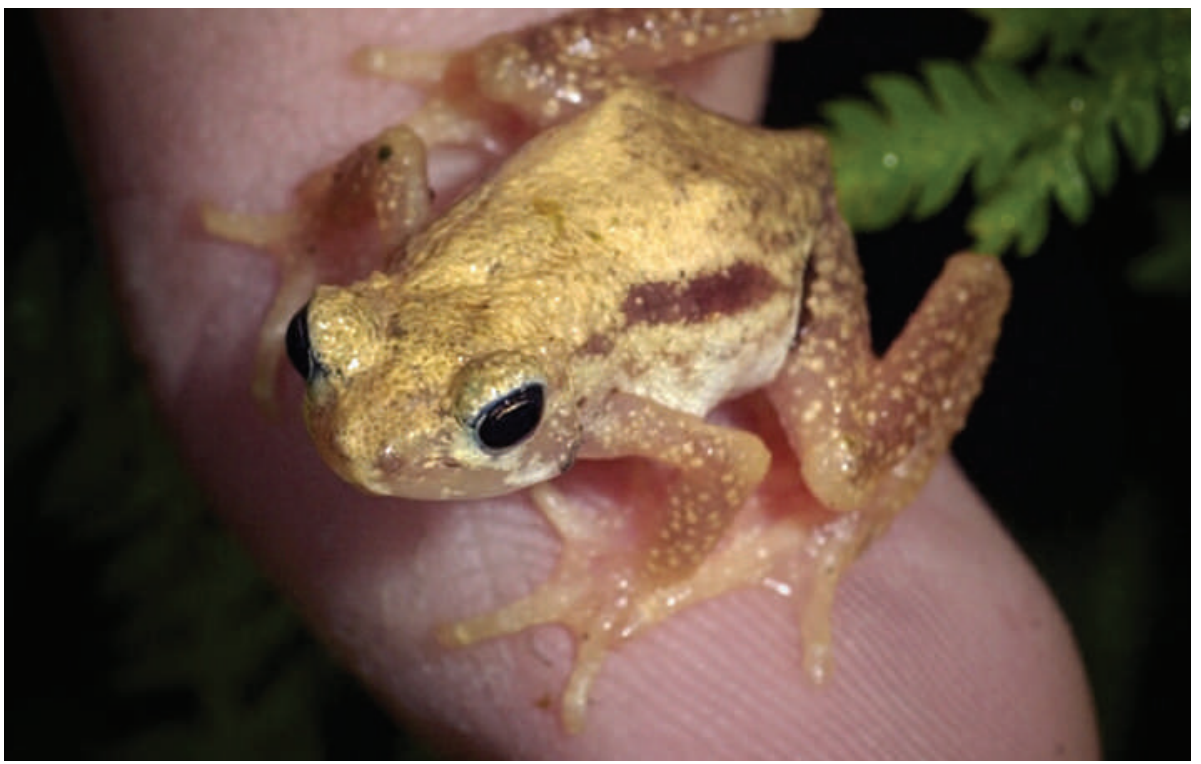

Construction of a dam in Tanzania helped drive the Kihansi spray toad to extinction in the wild.

go beyond the broad efforts made in the 2010 goal to increase the amount of land and marine areas that are under protection. Goals could also include the requirement for governments to have plans for dealing with specific causes of biodiversity loss, such as deforestation.

"One of the challenges and weakness of the current target is that it is not sufficiently clearly defined," says Mike Parr, secretary of the Alliance for Zero Extinction, a partnership of conservation organizations. Parr says the alliance wants a goal of stopping extinctions to be included in the 2020 targets.

The biodiversity convention will also specify the metrics that parties must use to measure progress towards agreed goals. Examples include the Red List of Threatened Species, published by the International Union for Conservation of Nature (see 'Species at risk'), and the Living Planet Index, produced by the conservation group WWF and the Zoological Society of London's Institute of Zoology.

"The 2010 target was adopted without identifying the means of achieving the target. It was more a political statement," says Ahmed Djoghlaf, executive secretary of the CBD. He says the same mistake will not be made in Nagoya.

Ben Collen, a researcher at the Institute of Zoology, says that a lack of investment from governments in developing new indicators, such as measuring genetic diversity, has meant that important aspects of biodiversity are deficient in data. "The indicators we have at the moment will slot into the new framework, but new ones will also have to be developed," he says.

The CBD will report its final assessment of countries' progress towards the 2010 goal in May next year, when it publishes the third edition of its Global Biodiversity Outlook. The assessment will be drawn from reports submitted by countries that are party to the convention. Djoghlaf says that of the 86 national reports received so far, "all say, without exception, that they have failed to reach the target".

But behind the gloomy headline figures lie considerable efforts to improve the state of the world's biodiversity.

Since the 2010 target was adopted in 2002, the Brazilian government has increased the proportion of land designated as protected by $25 \%$ and deforestation rates have been reduced by $60 \%$. It plans to identify further priority areas for conservation over the coming year.

And in Sweden, 9 new marine nature reserves were established between 2007 and 2008 , bringing the nation's total to 21 sites. A further seven marine protected areas and six no-fishing areas are planned by 2010.

A surge of further efforts can be expected before next October to ensure that countries will be able to report some positive news.

Natasha Gilbert

See Editorial, page 251, and whole biodiversity special at www.nature.com/darwin. 